\title{
MAGNETIC COMPONENTS CONTRIBUTING TO THE NRM OF MIDDLE SIWALIK RED BEDS
}

\author{
LISA TAUXE, DENNIS V. KENT and NEIL D. OPDYKE \\ Department of Geological Sciences of Columbia University and Lamont-Doherty Geological Observatory, \\ Palisades, NY 10964 (U.S.A.)
}

Received October 10,1979

Revised version received December 17, 1979

\begin{abstract}
The components of the NRM in Middle Siwalik red beds are carried by two phases of hematite, a red pigment phase and a specular hematite phase. We present evidence in the form of a conglomerate test that the specularite phase carries a remanence acquired during or shortly after deposition. The red pigment, however, post-dates deposition, in many cases by at least one reversal boundary. This secondary component has a higher coercivity but a lower blocking temperature in these rocks and can therefore be selectively removed by thermal demagnetization to reveal a primary magnetization useful for magnetostratigraphic studies.
\end{abstract}

\section{Introduction}

Siwalik Group red beds of India and Pakistan have been a fruitful source of Miocene mammalian fossils for over a century (see Pilbeam et al. [1] for complete description). Important conclusions concerning Miocene mammalian evolution rely on accurate dating and correlating of the many and widespread Siwalik exposures. The use of paleomagnetic stratig. raphy has proved invaluable for providing a precise temporal framework in which the fossil horizons can be located [2-4]. However, over the past fifteen years it has become evident that the natural remanent magnetization (NRM) of red beds of ten has little to do with the magnetic field direction at the time of deposition [5-8]. In view of the highly complex nature of red bed magnetism, it is crucial to identify the various components of the NRM and to show that the component isolated by the chosen demagnetization technique dates from near the time of deposition.

The red beds of the Middle Siwalik Group rocks have been studied with these questions in mind, and the results presented in this paper stress again the

Lamont-Doherty Geological Observatory Contribution No. 2941. need for careful analysis and rock magnetic studies when dealing with red beds.

\section{Components of the NRM}

Rocks of the Middle Siwalik Group can be divided into two classes on the basis of color and thermal demagnetization characteristics. There is a complete spectrum of rocks ranging in color from white to brick red, but the end members will be referred to as "grey" and "red". Zijderveld [14] diagrams and thermal demagnetization curves representative of the two groups are shown in Fig. 1.

The NRM of grey rocks has two components, as shown in Fig. 1a: a low blocking temperature component removed by thermal demagnetization at a few hundred degrees centigrade superimposed on a component of magnetization with a high blocking temper. ature $\left(680^{\circ} \mathrm{C}\right.$, characteristic of hematite) which decays linearly to the origin. Magnetic separates of grey rocks contain abundant dark magnetic grains which are opaque in thin section. Magnetization versus temperature $\left(J_{\mathrm{s}}-T\right)$ curves of the magnetic separates show no evidence for Curie temperatures lower than about $650^{\circ} \mathrm{C} . J_{\mathrm{s}}-T$ curves of separates with one grain of known magnetite added show a prominent 


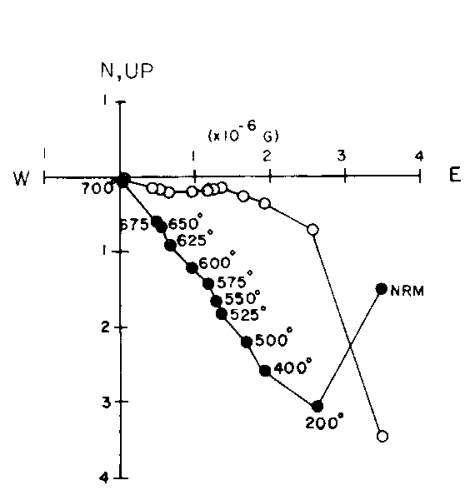

S, DOWN

o)

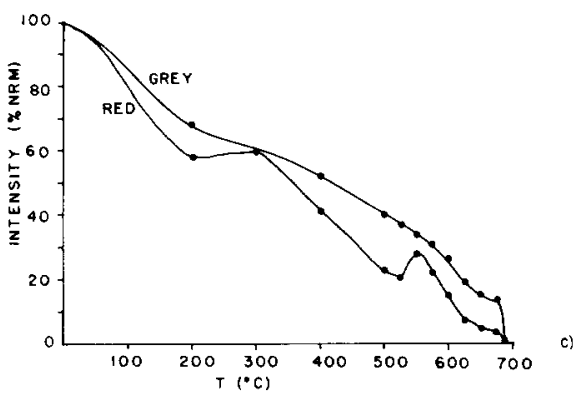

Fig. 1. Behavior of typical Middle Siwalik paleomagnetic specimens on thermal demagnetization. (a) Zijderveld diagram of a grey specimen. Solid circles are projections onto the horizontal plane, open circles onto the vertical plane. (b) Zijderveld diagram for a red specimen. (c) Thermal demagnetization curves for red and grey specimens.

intensity drop at the Curie temperature of magnetite $\left(580^{\circ} \mathrm{C}\right)$ and we therefore believe that if magnetite were present in our samples, even in very small quantities, then it would have been detected by this method. The dark grains are therefore tentatively assumed to be specular hematite and to be the carriers of the high blocking temperature remanence in grey rocks.

The straightforward behavior of grey rocks is contrasted with that of red rocks (Fig. 1b, c) which often show a reversal in the demagnetization trajectory between about 525 and $575^{\circ} \mathrm{C}$ (occasionally as high as $635^{\circ} \mathrm{C}$ ), marked by an increase in magnetization followed again by a linear decay to the origin at higher temperatures $\left(680^{\circ} \mathrm{C}\right)$. This behavior can be interpreted as the removal of an antiparallel component of magnetization, which, if it reflects a record of an oppositely polarized geomagnetic field implies a secondary origin for one of the remanence directions.
It is therefore imperative to identify the origin of the components of magnetization to establish which is likely to be primary and which is secondary.

\section{Chemical demagnetization}

Standard chemical demagnetization techniques as described by Collinson [9] and Park [10] cannot be performed on the Siwalik rocks since they are weakly cemented and readily disaggregate in acid or water. However, the coercivity and blocking temperatures of the various components can be determined using a modified version of the chemical demagnetization technique. This involves soaking the sample in acid, then repacking the disaggregated sample into plastic one inch cubes or mixing the dried powder with salt and pressing it into the shape of a standard one inch cylinder. The NRM is mechanically destroyed as a result, but the magnetic characteristics of the potential carriers of remanence can still be studied using isothermal remanence (IRM) acquisition characteristics.

Fig. $2 \mathrm{a}$ is an isothermal remanent magnetization (IRM) acquisition curve of a typical grey rock, which is constructed by placing the sample in successively higher applied fields and measuring the remanent magnetization at each step. The highest field available to us is $4750 \mathrm{Oe}$, not high enough to saturate hematite [11] but well above the usual saturating field of magnetite. The left side of the graph is constructed by subjecting the specimen to a field in the opposite sense (a backfield) in 100 Oe steps until the remanence acquired at 4750 Oe is reduced to zero. The field needed to reduce the magnetization to zero underestimates the remanent coercivity of the sample since the specimen was not saturated. However, the straight line fit of the backfield data suggests the presence of only one magnetic phase in this coercivity range and since that phase clearly does not reach saturation in fields up to $4750 \mathrm{Oe}$, it is probably hematite. This observation agrees with the conclusions drawn from the thermal demagnetization studies which show a high blocking temperature magnetization (see Fig. 1a).

Fig. $2 b$ illustrates the behavior of red rocks when subjected to the same treatment. Like the grey specimens, saturation is not reached in fields of $4750 \mathrm{Oe}$ and hematite is a dominant magnetic mineral, as sus- 


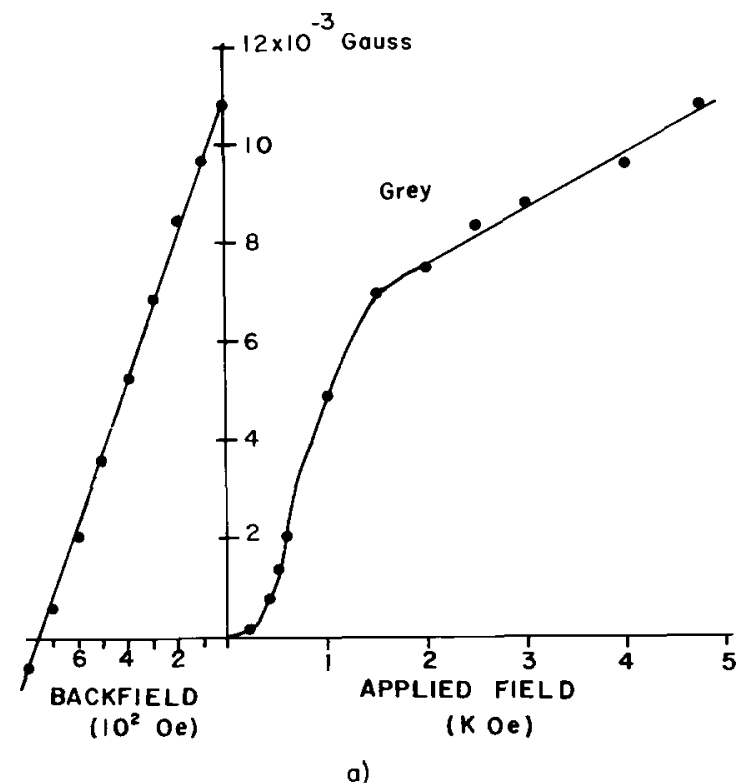

a)

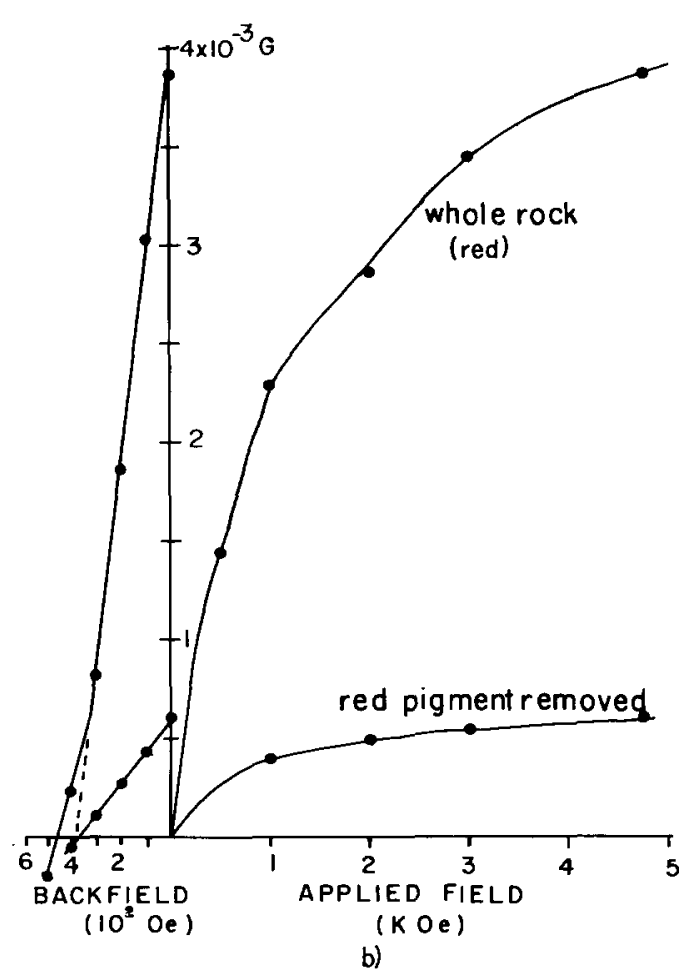

Fig. 2. IRM acquisition and backfield plots. (a) Behavior of a grey specimen. The specimen does not reach saturation in fields up to 4750 Oe and the backfield data are best fit by one straight line. (b) Behavior of a red specimen before and af ter removal of red pigment by acid treatment. Neither curve reaches saturation by 4750 Oe but the whole rock shows higher intensity than the acid treated specimen. Backfield data for the whole rock are best fit by two line segments, whereas data for the treated rock is best fit by one.

pected from the red color of the rock. It can be seen that the backfield curve is best characterized by two straight-line segments as opposed to the single line of grey rocks. This suggests that the antiparallel magnetization directions found in thermal demagnetization experiments may each be carried by separate magnetic phases in the red rocks.

The red specimen was then set in $12 \mathrm{~N} \mathrm{HCl}$, which served to remove the red pigment, leaving the now disaggregated specimen a color indistinguishable from the grey rocks. After reformation of the chemically treated specimen into a new specimen IRM acquisition and backfield curves were determined and are shown in Fig. $2 b$ for comparison with the untreated rock. The specimen now has a much reduced intensity showing that a large amount of the remanence can reside in the pigment. Although saturation is still not achieved by 4750 Oe, the backfield data can now be fitted by a single straight-line segment, and while the remanent coercivity of the treated sample is less than the overall remanent coercivity of the original red rock, it is identical to the projected value for the lower coercivity range.

The blocking temperatures of the two phases were determined by thermally demagnetizing an IRM acquired in 4750 Oe of both the acid treated specimen and a red specimen identical to it before acid treatment. The resulting demagnetization curves are plotted as percent initial IRM intensity (acquired in 4750 Oe) versus demagnetization temperature (Fig. 3 ). The difference between the two curves can be interpreted as the contribution of the red pigment. Because this diagram is a plot of percent IRM intensity and not absolute intensity the magnitude of this difference curve is not an indication of the magnitude of the red pigment contribution which can be quite large (see Fig. 2b). The blocking temperature of the red pigment, however, can be determined as the temperature 


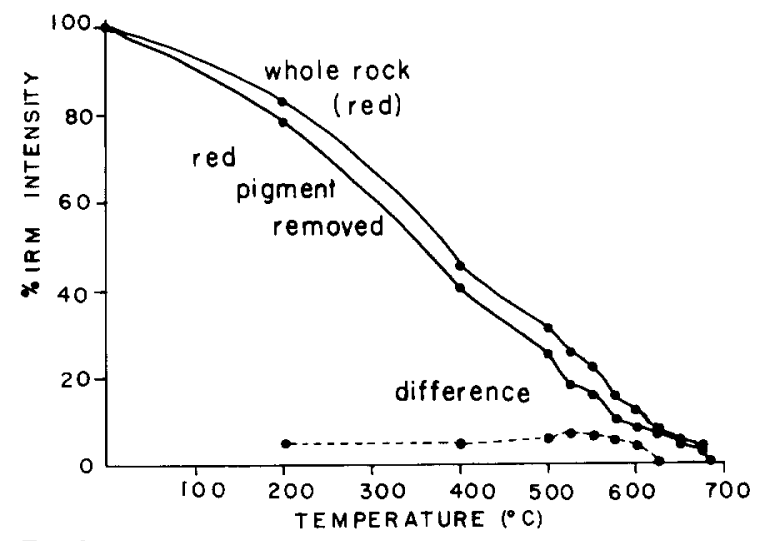

Fig. 3. Thermal demagnetization of IRM (4750 Oe) of a whole red specimen, and an identical specimen after removal of the red pigment. Blocking temperature for the red pigment is $625^{\circ} \mathrm{C}$ and the blocking temperature of the specularite (present in both whole rock and treated specimen) is $680^{\circ} \mathrm{C}$.

at which the difference curve goes to zero (around $625^{\circ} \mathrm{C}$ ). The blocking temperature of the specular hematite is higher (around $685^{\circ} \mathrm{C}$ ). It is therefore likely that the intensity increase often observed in red specimens (see Fig. 1b, c) is caused by the removal of the red pigment contribution which has a direction antiparallel to that of the specular hematite. Thus, if the specular hematite can be shown to carry a remanence penecontemporaneous to deposition, the red pigment clearly carries a remanence acquired significantly later.

\section{Conglomerate test}

Specular hematite can form authigenically in red beds [16] and we therefore cannot assume that it carries a detrital remanence without further evidence. In order to determine the timing of acquisition of the remanence carried by the specularite grains, we sampled a conglomerate bed composed of cobbles identical and contemporaneous to the Siwalik country rocks. It seems likely from field evidence that the conglomerate was formed by undercutting of a riverbank to form angular clods which were then buried without further transport, primarily because the rocks disaggregate readily in water. This must have occurred soon after original deposition of the cobbles as sediment.

At least three separately oriented hand samples were taken from each cobble to demonstrate magnet-

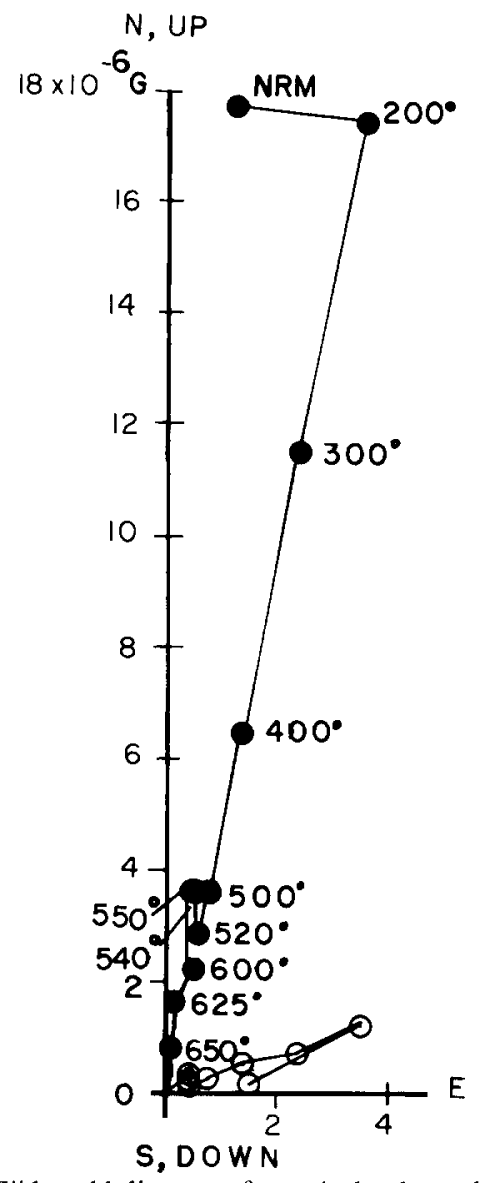

Fig. 4. Zijderveld diagram of a typical red conglomerate cobble on thermal demagnetization.

ic stability within each cobble. One specimen from each cobble was thermally demagnetized in stepwise fashion up to $650^{\circ} \mathrm{C}$ in order to compare its mag. netic behavior with that of the country rocks. Fig. 4 illustrates the similarity of behavior of a red conglomerate cobble specimen to that of the red country rock from which it presumably derived (Fig. 1b, c).

The individual specimen magnetizations were analysed using standard Fisher [15] statistics to give mean directions for each cobble. Cobble means with circles of confidence at the $95 \%$ confidence level are plotted on the stereonet shown in Fig. 5. It is clear from the figure that there is good within-cobble agreement (small circles of confidence) demonstrating the stability of the magnetic remanence carried by the cobbles. The magnetic direction of each cobble bears no resemblance to other cobbles, however, or to 


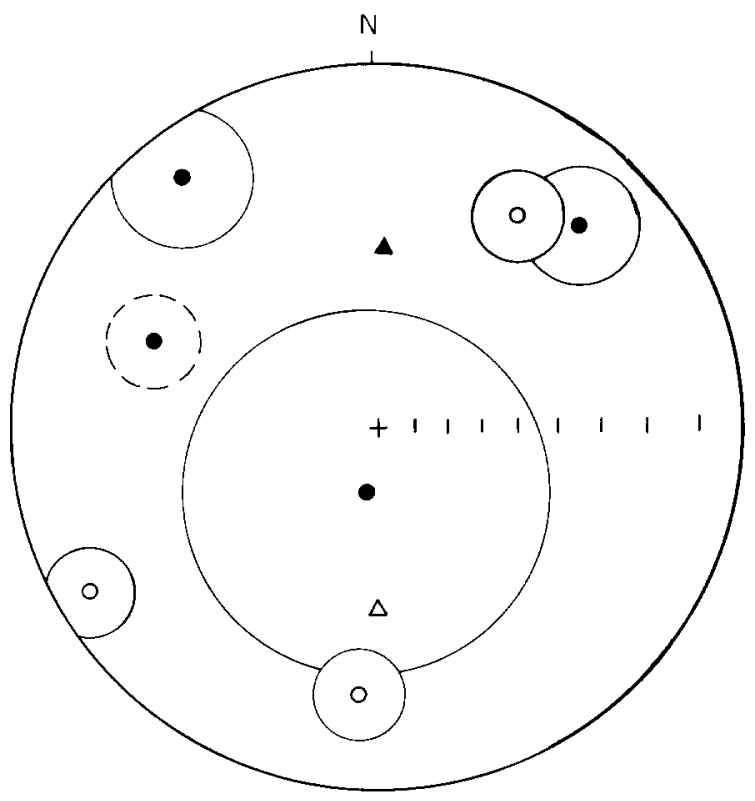

Fig. 5. Conglomerate test. Individual specimens from each cobble were averaged by Fisher statistics to obtain a mean direction. Each cobble having 3 or more separately oriented samples is plotted as a site mean (open or filled circles) with a circle of confidence at the $95 \%$ level of certainty. The site whose circle of confidence is a dashed line is the mean of only 2 samples. The circle encloses both points and has no statistical meaning. Open circles are projections on the upper hemisphere and solid circles are projections on the lower hemisphere.

the present dipole field direction (triangles). The mean of the cobble mean direction $(N=7)$ has a resultant vector length of only 1.51 , and the distribution of directions is random at the $99 \%$ level of confidence. This observation suggests that the remanence carried by the high blocking temperature component (specular hematite) was acquired before the conglomerate bed formed and hence was probably acquired penecontemporaneously with deposition.

Since we can now assume that the component of magnetization carried by the specular hematite is a primary one, the often antiparallel red pigment component must post-date deposition by at least one reversal boundary. There are cases of reversed red pigment components superimposed on normal specularite components (see Fig. Ib) hence these relatively high temperature secondary components are not a recent phenomenon. In this respect our results are similar to those presented by Roy and Park [6].

\section{Summary}

In this paper, we have presented evidence for two phases of hematite, a red pigment phase and a specular hematite phase, both of which contribute to the NRM of Siwalik red beds. We have shown that the red pigment is probably secondary and has a higher coercivity but a lower blocking temperature than the specular hematite allowing removal by thermal demagnetization. We have also presented evidence that the remanence carried by the specular hematite was in fact acquired during or shortly after deposition and therefore represents essentially a primary remanence.

\section{Consequences}

(1) Since the red pigment component, acquired significantly after deposition, has a higher coercivity than the specularite, alternating field demagnetization

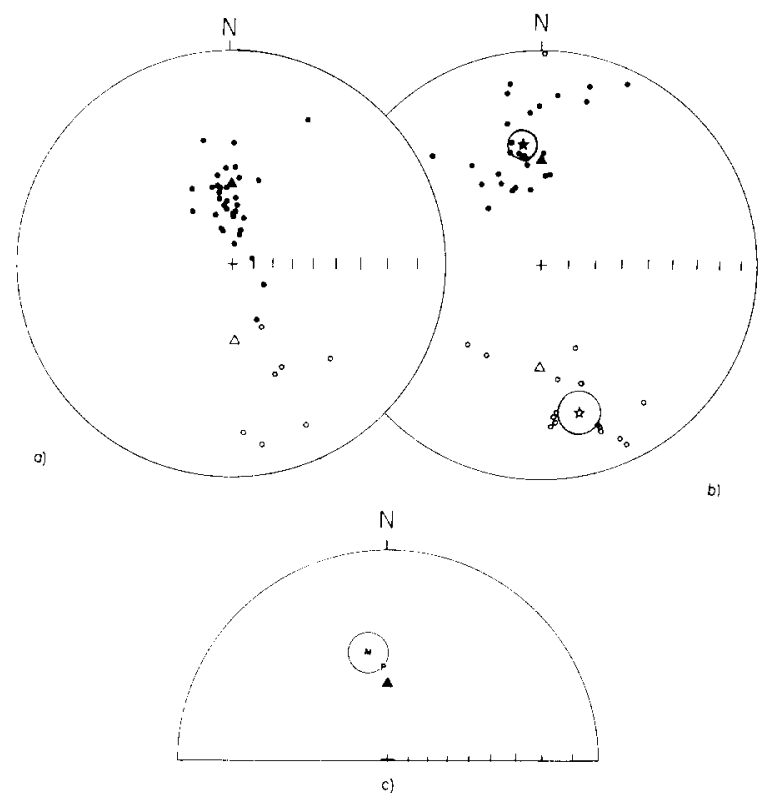

Fig. 6. Stereographic projections. (a) Siwalik section after AF demagnetization up to 450 Oe. $\wedge=$ present dipole field direction. Solid symbols are lower hemisphere projections and open symbols are upper hemisphere projections. (b) The same section after thermal demagnetization at $600^{\circ} \mathrm{C}$. (c) Comparison of mean of all sites (the antipodes of the reversed sites were used) from Fig. 6b (M), the paleofield for that age (P) as predicted by Molnar and Tapponnier [13], and the present dipole field direction $(\bullet)$. 
will not isolate the primary remanence, but may help improve within site grouping by removal of recently acquired low stability components. Fig. 6a shows the statistically significant sites of one Siwalik section after AF demagnetization up to 450 Oe. There are clearly both normal and reversed polarities but the streaking between the two polarities and dominance of the normal field direction on normal sites indicates that secondary overprint has not been removed.

(2) Thermal demagnetization isolates the primary remanence, if the rocks are cooled from a temperature exceeding the blocking temperature of the red pigment in a field-free space. Fig. $6 \mathrm{~b}$ illustrates the effectiveness of thermal demagnetization, in this case at $600^{\circ} \mathrm{C}$.

There is now no streaking between the normal and reversed polarities and the mean of the normal sites is significantly different from that of the present dipole field. The mean of the reversed sites is nearly antipodal to the mean of the normal sites. The conglomerate test suggests that the thermally demagnetized directions are essentially primary and hence may represent DRM. It has been reported that a DRM carried by specularite can be significantly shallower than the actual field direction due to the fact that the magnetization of hematite is carried in the basal plane [12]. Fig. $6 \mathrm{c}$ compares the dipole field direction expected for this time (Epoch 9) from plate tectonic reconstructions based on sea floor magnetic anomaly patterns [13] $(\mathrm{P})$ and the paleofield determined by averaging all the sites shown in Fig. 6b (M). The antipodes of the reversed sites were used in calculation. The measured field direction is somewhat shallower than the predicted field but they are not significantly different at the $95 \%$ level of certainty.

(3) An important consequence of these results for Siwalik rocks is that the characteristic magnetizations isolated for magnetostratigraphic purposes are primary and indicate the polarity of the prevailing magnetic field when the rock was formed. Magnetic sections derived from thermally demagnetized specimens can thus be used to date and correlate Siwalik sequences.

\section{Acknowledgements}

We would like to acknowledge J.C. Liddicoat and J.D. Hays for critically reviewing the manuscript.
This work was supported by NSF grants EAR 78 . 05493 and BNS 772-5984.

\section{References}

1 D. Pilbeam, J. Barry, G. Meyer, I Shah, M. Pickford, W.W. Bishop, H. Thomas and L. Jacobs, Geology and paleontology of Neogene strata of Pakistan, Nature 270 (1977) 684 .

2 D. Pilbeam, A. Behrensmeyer, J. Barry and I. Shah (in press).

3 J. Barndt, N.M. Johnson, G.D. Johnson, N.D. Opdyke, E.H. Lindsay and R.A.K. Tahirkheli, The magnetic stratigraphy and age of the Siwalik Group near Dhok Pathan Village, Potwar Plateau, Pakistan, Earth Planet. Sci. Lett. 41 (1978) 355.

4 N.D. Opdyke, E.H. Lindsay, G.D. Johnson, N.M. Johnson, R.A.K. Tahirkheli and M.A. Mirza, Magnetic polarity stratigraphy and vertebrate paleontology of the upper Siwalik subgroup of northern Pakistan, Palaeogeogr., Palaeoclimatol., Palaeoecol. 27 (1979) 1.

5 J.L. Roy and W.A. Robertson, Evidence for diagenetic remanent magnetization of the Marangouin Formation, Can. J. Earth Sci. 5 (1968) 275

6 J.L. Roy and J.K. Park, Red beds: DRM or CRM?, Earth Planet. Sci. Lett. 17 (1972) 211.

7 D.W. Collinson, Origin of remanent magnetization and initial susceptibility of certain red sandstones, Geophys. J. R. Astron. Soc. 9 (1965) 203.

8 E.E. Larson and T.R. Walker, Development of chemical remanent magnetization during early stages of red bed formation in Late Cenozoic sediments, Baja California, Geol. Soc. Am. Bull. 86 (1976) 639.

9 D.W. Collinson, Chemical demagnetization, in: Methods in Paleomagnetism, D.W. Collinson, K.M. Creer and S.K. Runcorn, eds. (Elsevier, Amsterdam, 1967) 306.

10 J.K. Park, Acid leaching of red beds and the relative stability of the red and black magnetic components, Can. J. Earth Sci. 7 (1970) 1086.

11 D.J. Dunlop, Magnetic properties of fine particle hematite, Ann. Geophys. 27 (1971) 269

12 D.P. Elston and M.E. Purucker, Detrital magnetization in red beds of the Moenkopi Formation (Triassic), Gray Mountain, Arizona, J. Geophys. Res. 84 (1979) 1653.

13 P. Molnar and P. Tapponnier, Cenozoic tectonics of Asia: effects of a continental collision, Science 189 (1975) 419.

14 J.D.A. Zijderveld, A.C. demagnetization of rocks: analysis of results, in: Methods in Paleomagnetism, D.W. Collinson, K.M. Creer and S.K. Runcorn, eds. (Elsevier, Amsterdam, 1967) 254-286.

15 R.A. Fisher, Dispersion on a sphere, Proc. R. Soc. London, Ser. A, 217 (1953) 295-305. 